Portland State University

PDXScholar

Spring 1-1-2012

\title{
Child Welfare and Delinquency: Examining \\ Differences in First-Time Referrals of Crossover Youth within the Juvenile Justice System
}

Courtney Nicole Shrifter

Portland State University

Follow this and additional works at: https://pdxscholar.library.pdx.edu/open_access_etds

Part of the Criminology Commons, Family, Life Course, and Society Commons, and the Social Welfare Commons

Let us know how access to this document benefits you.

\section{Recommended Citation}

Shrifter, Courtney Nicole, "Child Welfare and Delinquency: Examining Differences in First-Time Referrals of Crossover Youth within the Juvenile Justice System" (2012). Dissertations and Theses. Paper 649.

https://doi.org/10.15760/etd.649

This Thesis is brought to you for free and open access. It has been accepted for inclusion in Dissertations and Theses by an authorized administrator of PDXScholar. Please contact us if we can make this document more accessible: pdxscholar@pdx.edu. 
Child Welfare and Delinquency: Examining Differences in First-Time Referrals of Crossover Youth within the Juvenile Justice System

by

Courtney Nicole Shrifter

A thesis submitted in partial fulfillment of the requirements for the degree of

\author{
Master of Science \\ in \\ Criminology and Criminal Justice
}

Thesis Committee:

William Feyerherm, Chair

Laura Hickman

Hyeyoung Woo

Portland State University

(C)2012 


\begin{abstract}
The link between child welfare and juvenile justice is well established, with over forty years of research that focuses on the increased risk of delinquency associated with child maltreatment. However, with over 700,000 children in the United States being victims of abuse and/or neglect in 2010 (DHHS, 2011), it is important to continue investigating this connection. Few studies are able to identify the same youth in both systems, therefore this study provides the unique opportunity using child welfare and juvenile justice administrative data from Oregon, to compare juvenile offenders that have been in the child welfare system, otherwise known as "Crossover" youth, to Non-Crossover juvenile offenders. The study attempted to examine if Crossover youth differ in terms of demographics, as well as if they committed offenses with higher severity scores than Non-Crossover youth. It also investigated whether an individual's status as a child welfare youth impact processing decisions in the juvenile justice system. Results indicate that Crossover youth have a higher percentage of females, African Americans, and are significantly younger. Crossover youth also have higher severity scores than noncrossover youth, and have a higher percentage of more intense adjudicated delinquent sanctions. Limitations of these findings and suggestions for further research are discussed.
\end{abstract}




\section{Acknowledgements}

I wish to extend my deepest gratitude to a number of people for making this thesis possible:

I would like to thank the Department of Human Services and the Juvenile Justice System for the state of Oregon for allowing me to examine their data. Exploring this data allowed the rare opportunity to study how agencies report their information.

Dr. William Feyerherm, thank you for taking the time to include me on your research projects. Providing me with valuable quantitative data analysis experience. Your guidance, support, and suggestions over the past 6 months it took to complete this thesis were invaluable.

Thank you to Dr. Laura Hickman and Dr. Hyeyoung Woo for being my readers and part of my thesis committee. I appreciate the time you both took in providing feedback and helping me through this process.

And finally, thank you to my family for your guidance and support throughout my education. I appreciate that you have always been there to support me in all my endeavors. 


\section{Table of Contents}

Abstract............................................................... i

Acknowledgements...................................................... ii

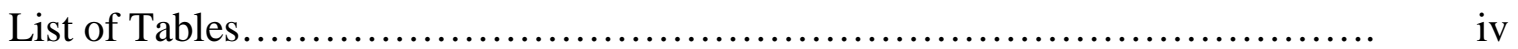

Chapter 1:

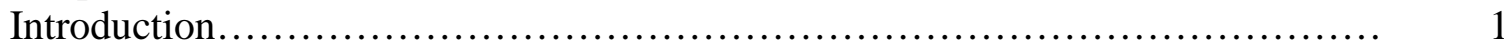

Chapter 2:

Review of Literature..................................................... 3

Chapter 3:

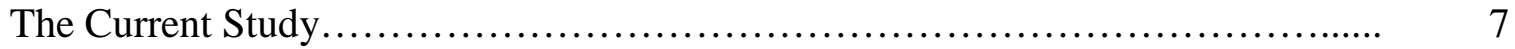

Chapter 4:

Methods.................................................................... 9

Chapter 5:

Results................................................................ 15

Chapter 6:

Discussion............................................................ 27

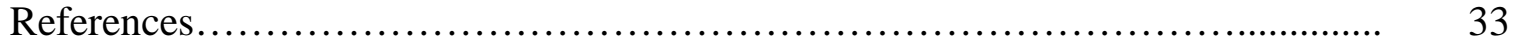

Appendices

A. Juvenile Justice Information Systems Severity Scores.............. 36

B. Juvenile Justice Information Systems Disposition Categories......... 37

C. Human Subjects Approval.................................... 38 


\section{List of Tables}

Table 1. Independent Samples T-Test for Demographics...................... 15

Table 2. Types of Threats to Child Welfare................................... 17

Table 3. Demographics by Polyvictimization Status of Threats to Child Welfare.... 17

Table 4. Demographics of Pure Threat Types ............................... 18

Table 5. Offense Type for Crossover and Non-Crossover Youth.................. 20

Table 6. Severity Code for Crossover and Non-Crossover Youth................. 20

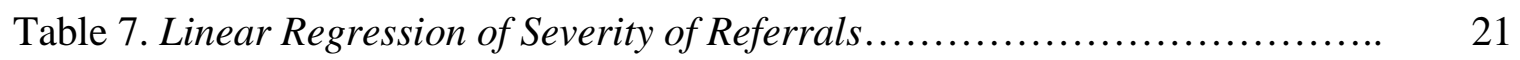

Table 8. Overall Case Outcomes by Crossover Status.......................... 23

Table 9. Overall Case Outcomes for Not Petitioned and Petitioned by Crossover Status................................................................ 25

Table 10. Case Dispositions among Not Petitioned Cases by Crossover Status...... 25

Table 11. Case Dispositions among Petitioned Cases by Crossover Status.......... 25

Table 12. Case Dispositions among Adjudicated Delinquent Cases by Crossover Status................................................................... 26 


\section{Chapter 1: Introduction}

In 2010, an estimated 700,000 children in the United States were found to be victims of maltreatment (9.2 victims per 1,000 children in the population) (U.S. Department of Health and Human Services [DHHS], 2011). As researchers and child welfare professionals dedicated to the well being of young people know, childhood maltreatment and neglect can cause a host of short- and long-term negative consequences (Bilchik \& Nash, 2008). Therefore, researchers and practitioners from both child welfare and criminal justice have been progressively more concerned about the increased likelihood of child welfare youth to be involved in the juvenile justice system (Brezina, 1998; Herz, Ryan, \& Bilchik, 2010; Nash \& Bilchik, 2009; Smith \& Thornberry, 1995). Although no single factor by itself is likely to account for the development of criminal behavior, the importance of childhood maltreatment as a risk factor for subsequent delinquency and violence has become increasingly recognized (Widom, 2003). Purpose and Specific Aims

Over the past forty years, researchers have repeatedly demonstrated the connection between childhood maltreatment and delinquency (Brezina, 1998; Herz et al., 2010; Nash \& Bilchik, 2009; Smith \& Thornberry, 1995). In an effort to provide further insight on this connection, it may be beneficial to examine any potential differences that delinquent child welfare youth have from the general delinquent population. Do youth originating from the child welfare system represent a unique demographic (i.e. gender, race, age) subgroup within the juvenile justice system? Do Crossover youth commit a different (more serious) set of offenses? Does the individual's status as a child welfare 
youth impact processing decisions (dispositions) in the juvenile justice system? This current study addresses these important questions.

Statewide data for Oregon on both juvenile referrals (and dispositions), along with founded cases of child welfare maltreatment was obtained for the present study. Administrative staff in the two agencies involved constructed a common identifier of juvenile justice youth who have also had contact with the child welfare department. With a deeper understanding of these issues, policy makers may be able to make more informed decisions about policies and laws effecting this particular population, with the goal of reducing the risk of delinquency. 


\section{Chapter 2: Review of Literature}

Adolescents involved in both the child welfare, and juvenile justice system are referred to as "Crossover" youth. Although, most delinquents are not crossover youth, research has shown that youth coming from the child welfare system are much more likely to becoming a delinquent. Numerous studies indicate youth exposed to abuse and neglect are at an increased risk of delinquency (Bilchik \& Nash, 2008; Bolton, Reich, \& Guitierris, 1977; Ryan, Herz, Hernandez, \& Marshall, 2007; Smith \& Thornberry, 1995). However, prevalence of Crossover youths nationwide is difficult to ascertain. Very few jurisdictions are equipped to systematically track the number of crossover youths, much less their outcomes. Studies estimate that between $6 \%$ and $29 \%$ of child welfare youth engage in delinquent behavior (Bolton, et al., 1977; Ryan et al., 2007; Smith \& Thornberry, 1995). However, due to the fact that Oregon's systems created common identifiers, this study was able to track the number of crossover youths and their outcomes. Much of the research on crossover youth often categorizes crossover types into neglect and abuse or maltreatment for their studies. Therefore, it may be important to examine whether crossover threat types such as neglect, physical abuse, or sex abuse and exploitation affect the extent to which they are involved in the juvenile justice system.

Young people known to both systems are mostly male, but crossover contributes disproportionately to females entering the juvenile justice system. Females are the fastest growing population in the juvenile justice system compared to all other demographic characteristics, which is also true of female adult offenders (Bilchik \& Nash, 2008). In Los Angeles, a larger proportion of females enter the juvenile justice system from child welfare than from any other single referral source (Ryan et al., 2007). Female Crossover 
youths also suffer from a lack of gender-specific programming, and the juvenile justice system often has limited housing capabilities for females (Bilchik \& Nash, 2008). Thus, it is extremely important to examine whether this is happening in Oregon, where the housing capabilities for female offenders are significantly less.

Race in particular has been an important predictor as to whether a youth will become known to the child welfare and juvenile justice systems (Bilchik \& Nash, 2008). Nationwide, African-Americans represent $26 \%$ of juvenile arrests, $44 \%$ of youth who are detained, $46 \%$ of the youth who are judicially waived to criminal court, and $58 \%$ of the youth admitted to state prisons (Center on Juvenile and Criminal Justice, 2011). Some research suggests that crossover from child welfare to the juvenile justice system is a significant contributor to disproportionate minority contact with the juvenile justice system. In one study African-American youths were twice as likely as similarly situated white youths in the child welfare system to be arrested (Herz \& Ryan, 2008). In Los Angeles, African-American youths are $14 \%$ of the total population; but make up $30 \%$ of the child welfare population, and represent $54 \%$ of the total population that moves from child welfare to the juvenile justice system (Ryan, et al., 2007). Investigating the affects of race further, in a population such as Oregon, where the African American population is significantly lower than the nation $(1.8 \%$ vs. $12.6 \%)$ will provide more clarity to issues of racial disparity within the juvenile justice system.

There is no uniform national age from which a child is accountable in the juvenile court system; this varies between states, with many setting 10 as the minimum. Most research on the average age of serious male offenders at their first contact with the juvenile justice system is around 14.5 years of age (Office of Juvenile Justice and 
Delinquency Prevention [OJJDP], 2008). Past research on dependent youth have found that they are arrested more often and begin offending at an earlier age relative to nondependent youth (Ryan \& Testa, 2005; Kelly, Thornberry, \& Smith, 1997). In a series of studies, researchers also found that abused and neglected youth were younger at the time of their first arrest (Maxfield \&Widom, 1996; Widom, 1989; 1992). That being said, it is important to investigate whether these differences between when Crossover youth and Non-Crossover youth enter the juvenile justice system still exist in order to develop safeguards to combat the disparity.

Although most research agrees that the majority of youth in the child welfare system do not become delinquent, there has been some inconsistency about whether Crossover youth commit more violent or serious crimes. Armstrong (1998) found that Crossover youth averaged lesser levels of charged offenses than Non-Crossover youth. Another study found that Crossover youth were no different in offense seriousness than the juvenile population at large (Scrivner, 2002). However, other research which compares violent delinquents with less violent peers, found that 75 percent of the violent children had been severely physically abused, compared to only 33 percent of the less violent group (Lewis, 1983). Also in a study on the so-called "cycle of violence" by Widom and Maxfield (2001), abused and neglected youth were 11 times more likely to be arrested for a violent crime as a juvenile than were their non-maltreated counterparts. More recently Thornberry (2008) demonstrated that Crossover youth are more likely to commit violent or serious offenses than those with no history of abuse or neglect. Therefore, it is still unclear whether Crossover youth really differ from those with no child welfare involvement in terms of crime severity. A possible reason for the 
inconsistency could be due to the fact that the studies done by Armstrong (1998) and Scrivner (2002) were primarily reviewing youths at the formal processing decision point; rather than Widom and Maxfield (2001), and Thornberry (2008), who were examining all referrals to the juvenile justice system. However, since this study is examining all referrals to the juvenile justice system, as well as reviewing multiple decision points, it hopes to shed light on these inconsistent findings.

Despite the consensus that maltreatment increases the risk of delinquency, most research on this connection virtually ends at the point of arrest. The research on the outcomes of child welfare youth in the juvenile justice system is often far more limited; some professionals speculate that this may because there is lack of collaboration between the child welfare and juvenile justice systems to identify these children (Freundlich \& Morris, 2004). In general, the few studies that focus on maltreated children in the juvenile justice system indicate that the status as a Crossover youth negatively influences decision-making (Conger \& Ross, 2001, Freundlich \& Morris, 2004). However, most of this research focuses specifically on foster youth. This is a population likely to include some youth who have been victims of maltreatment, but may also include other youth who have lost families for a variety of reasons other than mistreatment. Freundlich and Morris (2004) concluded that the offenses associated with dependent youth entering the juvenile justice system were less serious compared to nondependent delinquents and that many stakeholders believed crossover youth were treated differently than their delinquency-only counterparts. Therefore, there is a need to examine the outcomes of overall child welfare youth at multiple decision points in the juvenile justice system. 


\section{Chapter 3: The Current Study}

In summary, while the above studies are informative to our understanding about some of the links and connections between child welfare and the juvenile justice system, there is still more research to be done. The present study examines the question of whether adolescents from the child welfare system differ (with regard to certain demographics) from the Non-Crossover adolescents that enter the juvenile justice system. Following that, it next examines the types of threats (maltreatment), which were "founded" for this group, and then investigates whether Crossover youth commit more severe offenses than Non-Crossover youth. Lastly, it examines whether the individual's status as a child welfare youth impacts processing decisions (dispositions) in the juvenile justice system.

This study hypothesizes that adolescents coming from the child welfare system will have different pathways in the juvenile justice system, than adolescents who have had no contact with the child welfare system. Consistent with previous research, this study anticipates Crossover youth will have a higher proportion of females, African Americans, and a younger population (Bilchik \& Nash, 2008; Ryan et al., 2007; Herz \& Ryan, 2008). In terms of the allegations which bring them to the juvenile justice system, this study also expects to see Crossover youth with higher severity scores, as the more recent research suggests (Thornberry, 2008).

Lastly, this study anticipates that Crossover youth will experience more intense sanctions (as measured by dispositions) in the juvenile justice system compared with Non-Crossover youth. It might be assumed that if youth have been through mild forms of treatment services while in the child welfare system, it may be expected that judges, 
district attorneys, and probation officers would see fewer viable options for handling these kids. Therefore, giving them more intense sanctions. This reasoning comes from the assumptions about the willingness (or lack thereof) of foster parents to remain involved with a delinquency case and from the literature on stereotypes and juvenile justice decision-making(Conger \& Ross, 2001, Freundlich \& Morris, 2004). The literature summarized by Feld (1999), concludes court officials impose more severe sanctions when youth are not perceived to come from "good" families. Therefore, this study expects to find that Crossover youth will experience a more intense level of dispositions, particularly at the adjudicated delinquent decision point.

This study will be doing a comparative analysis of Crossover youth and NonCrossover youth at their first-time referral within the juvenile justice system. The measures that will be examined for this study are: crossover youth status, crossover threat type, Oregon Revised Statue (ORS) severity types and scores of the referral/offense, and the most intense disposition outcome (such as probation, plea bargain, dismissed, etc.). Demographics such as gender, race, and age at referral/offense will also be examined. 


\section{Chapter 4: Methods}

Sample

The sample for this study consisted of 151,860 juvenile referrals and their associated dispositions from the state of Oregon. Seven percent $(10,635)$ of the offenders classified as Crossover youth, which is consistent with prior research (Herz et al., 2007; Smith \& Thornberry, 1995). Sources of the data used for this study include administrative records for all children involved with the Department of Human Services and the Juvenile Justice System for the state of Oregon. The delinquency records were collected from 1998 to 2010 and represent first time offenses for all minors who have had contact with Oregon's Juvenile Justice System.

The delinquency records include demographic characteristics (gender, race/ethnicity, birthdates), as well as referral and disposition data. Gender among the sample consisted of approximately of $36 \%$ female and $64 \%$ males. The majority of the youth in this sample were white $(74.7 \%)$, while the remaining youth were African American (4.1\%), Asian (1.6\%), Hispanic (12.6\%), Native American (1.8\%), or Others/Unknown (5.2\%). As a point of reference, the African American population for the United States is approximately $12.6 \%$, but in Oregon the African American population is only $1.8 \%$ (2010 U.S. Census Data). In an effort to be consistent with juvenile justice national reporting, youth included in this study were at least 10 years of age or older, with the mean age being 14.65 years old at the time of their first referral (SD $=1.832$ ). The child welfare and juvenile justice records share a unique identifier. This was originally created for a special crossover research project by administrative staff in the two agencies. Records of each system do not routinely contain a shared identifier. 
Thus, this sample provided the unique opportunity to identify minors who have had contact with both systems.

\section{Procedure and Measures}

Gender. The gender variable originally had 159 missing cases; however, after determining that the missing cases were random through a cross-tabular analysis, and there were so few missing (approximately .09\%), they were deleted from the sample using list wise deletion. The remaining cases were recoded into two dummy variables, female $(1=$ female, $0=$ not female $)$, and male $(1=$ male, $0=$ not male $)$.

Race. The race variable originally consisted of two independent variables, race and ethnicity. The race variable had five different categories: White, African American, Asian, Native American, and Others/Unknown. Ethnicity was coded as Hispanic or none. For the purpose of this study (and for the larger study that provided the basic data) ethnicity and race were merged, so that if a juvenile was coded as Hispanic that code took precedence over the race coding. After that, each of the resulting race/ethnicity categories were recoded into dummy variables, where one represented that particular race/ethnicity and zero represented all others.

Age at Referral. Age at referral originally ranged from age 0 to 32, undoubtedly reflecting some data entry errors, as well as situations that did not really involve a juvenile delinquency allegation. In order to be consistent with national reporting of juvenile justice, this variable was recoded to only include ages 10 and older. Also, the youth under 10 represented such a small number of the population, and appeared to be random using cross-tabular analysis; therefore, the researcher was confident it would not skew the results to discard those data points. 
Offense Type. This variable represents the type of offense that is the most serious offense of that referral, categorized according to Oregon Revised Statute (ORS), Criminal Code of Oregon, as defined by the Oregon Legislature. This variable was also recoded to only include four categories: Status, Violation, Misdemeanor, and Felony, because the remaining categories had zero cases.

Severity Scores. This variable represents a score for the offense category that is the most serious offense of that referral, categorized according to Oregon Revised Statute (ORS), Criminal Code of Oregon, as defined by the Oregon Legislature. The ranking of offenses according to severity was conducted by the Juvenile Justice Information System (JJIS) steering committee and is published in the JJIS report series. Each offense's category, type, and class determine the severity score. (See Appendix A) This variable was also recoded to match the severity scores from JJIS for Oregon. Therefore, the small number of cases representing dependency allegations and out of state crimes were deleted from the juvenile justice data entries through list wise deletion.

Dispositions Categories. This variable represents the sanction that was given for the most intense referral. This variable was recoded from 95 detailed disposition categories to be grouped into 6 disposition reporting categories (See Appendix B). This was recoded to be consistent with the standard developed by the JJIS Data and Evaluation Committee, and modeled after national reporting standards. Approximately $2 \%$ of the entries for this variable had to be deleted because it represented a category that no longer exists. Using cross-tabular analysis, it was verified that these cases did not represent a pattern when examined through other variables. It is important to note that the disposition categories found in Appendix B refer to dispositions at multiple decision 
points within the juvenile justice system. Categories are listed from least to most intense level of juvenile justice intervention in two main layers. The first layer is those cases resolved informally, or not petitioned including: review and close and authorized diversion programs or other informal disposition. The second layer are those cases in which a petition of delinquency was filed with the court, and in which that petition was resolved by one of several means: dismissed, alternative process/plea bargain, adjudicated delinquent, and adult court (See Appendix B). This study also looks specifically at the adjudicated delinquent disposition, which includes: probation, custody transfer to other agency, and youth correctional facility.

Crossover Youth. This variable was created to represent the youth that had been 'involved' in both the child welfare system and the juvenile justice system. The mechanism of 'involvement' in juvenile justice was a formal referral into the juvenile court. In child welfare the 'involvement' meant that a formal allegation of child maltreatment was investigated and 'founded' by the Department of Human Services (DHS). The nature of the founded cases are described briefly below, but the set of information only contains those cases in which the child was formally and officially found to have been the victim of child maltreatment. Cases of allegations or suspicions are not included. Administrative staff from the two agency information systems found sets of variables (e.g. date of birth, race, ethnicity, gender, surname, etc.), which they were confident would permit them to match the youth and give the DHS files when they matched, a new data field containing the JJIS number. A new variable was then created that represented all child welfare youth that contained a matching juvenile justice youth identifier, which became known as the Crossover variable. For purposes of this study, 
this variable was then recoded as a dummy variable $(1=$ Crossover, $0=$ Non-Crossover $)$. Once all variables went through data cleaning and recoding, the data from both systems were merged using the Crossover variable. It should be noted that this variable does not indicate which system 'came first' or that the two systems had overlapping jurisdiction at some point in the child's life. It simply means that these youth have had experience in both child serving systems.

Crossover Threat Type. This variable represents the types of threats a crossover youth may experience within the child welfare system. This refers to the nature of the maltreatment that was 'founded' within the Child Welfare System. It is important to recognize that the only information this study had access to in the Child Welfare system were the records of maltreatment that were investigated and substantiated through an official review process. This study does not have access to alleged maltreatment or to other allegations within the cases that were unfounded. In other words this is an extremely conservative view of the likely mistreatment of these youth. This variable originally consisted of six different categories: Abandonment, Mental Injury, Neglect, Physical Abuse, Sexual Abuse/Exploitation, and Threat of Harm. For the purpose of this study each crossover youth type category was recoded into dummy variables, where one represented that particular type of threat and zero represented all others. It is important to note these categories are not mutually exclusive; therefore, a youth could report more than one type of threat. Therefore, these variables were recoded into pure threat types, referring to cases where only one threat type was documented; multiple threat types (Non-SA), referring all cases where more than one threat type was documented but no combination contained a sexual abuse/exploitation threat type; and multiple threat types 
(SA plus), referring to all cases where more than one threat type was documented and at least one threat type documented was a sexual abuse/exploitation threat type. Recoding these variables in this way allowed this category to become mutually exclusive. 


\section{Chapter 5: Results}

\section{Demographic Characteristics}

Of the 151,860 unique minors referred to Oregon's Juvenile Justice System between 1998 and 2010, $7 \%(10,635)$ of the offenders classified as Crossover youth. This is consistent with prior research (Herz et al., 2007; Smith \& Thornberry, 1995). The demographic characteristics of both the Crossover youth and Non-Crossover youth are displayed in Table 1 below. With regard to demographic characteristics, Crossover youth have a higher percentage of females (48.7\% vs. 35\%), African Americans (7.6\% vs.

$3.8 \%)$, and are significantly younger ( $\mathrm{M}=13.44$ vs. 14.74), than Non-Crossover youth.

All these results were statistically significant.

Table 1

Demographics by Crossover Status

\begin{tabular}{|c|c|c|c|c|c|c|}
\hline \multirow[t]{2}{*}{ Measures } & \multicolumn{2}{|c|}{ Crossover Youth } & \multicolumn{2}{|c|}{$\begin{array}{c}\text { Non-Crossover } \\
\text { Youth }\end{array}$} & \multicolumn{2}{|c|}{ Totals } \\
\hline & $N$ & $\%$ & $N$ & $\%$ & $N$ & $\%$ \\
\hline \multicolumn{7}{|l|}{ Gender } \\
\hline Female & 5,177 & 48.7 & 49,492 & 35 & 54,669 & 64 \\
\hline Male & 5,458 & 51.3 & 91,733 & 65 & 97,191 & 36 \\
\hline \multicolumn{7}{|l|}{ Race } \\
\hline White & 7,904 & 74.3 & 105,577 & 74.8 & 113,481 & 74.7 \\
\hline African American & 804 & 7.6 & 5,409 & 3.8 & 6,213 & 4.1 \\
\hline Asian & 126 & 1.2 & 2,317 & 1.6 & 2,443 & 1.6 \\
\hline Hispanic & 1,094 & 10.3 & 18,054 & 12.8 & 19,148 & 12.6 \\
\hline Native American & 279 & 2.6 & 2,386 & 1.7 & 2,665 & 1.8 \\
\hline Others/Unknown & 428 & 4.0 & 7,482 & 5.3 & 7,910 & 5.2 \\
\hline
\end{tabular}




\section{Crossover Threat Type}

Table 2 reports the percent of youth, broken down by each type of threat documented by child welfare, within Crossover youth. The highest proportion of Crossover youth in this sample had experienced some Threat of Harm (41.9\%), followed by with Neglect (20.3\%), Physical Abuse (16.8\%), and Sexual Abuse/Exploitation $(15.5 \%)$. It is important to note these categories are not mutually exclusive; therefore, a youth could report more than one type of threat. The demographic characteristics of threat types by polyvictimization status are displayed in Table 3. Crossover youth who had one threat documented are relatively similar to that of the general Crossover youth population. This is somewhat expected being that the majority of Crossover youth only have one threat documented (88\%). With regard to demographic characteristics, multiple threats in which one of those threats is sexual abuse/exploitation have a higher percentage of females (78.4\%) and a lower percentage of African Americans (4.5\%). For all the findings refer to Table 3 .

Table 4 represents demographic characteristics for all pure threat types, referring to cases where youth had only one threat type documented. With regard to demographic characteristics, Crossover youth who have a pure threat type of abandonment have a lower percentage of female $(37 \%)$ and White $(63 \%)$ populations and a higher percentage of Hispanic (15.2\%) populations compared to all other pure threat types. Although the findings for multiple threats in which one of those threats is sexual abuse/exploitation and the pure abandonment threat type produced interesting results in terms of demographic characteristics, the individual Crossover threat types did not produce substantive 
differences in the later analyses of offense severity or case dispositions; therefore, later tables do not differentiate Crossover youth by type of threat suffered.

Table 2

Types of Threats to Child Welfare

\begin{tabular}{lcc}
\hline Crossover Youth & Percent of Findings* & $\begin{array}{c}\text { Percent of Crossover } \\
\text { Youth* } \\
N=10,635\end{array}$ \\
\hline Abandonment & $N=11,994$ & $1.3 \%$ \\
Mental Injury & $1.2 \%$ & $4.9 \%$ \\
Neglect & $4.3 \%$ & $22.8 \%$ \\
Physical Abuse & $20.3 \%$ & $18.8 \%$ \\
Sexual Abuse/Exploitation & $16.8 \%$ & $17.4 \%$ \\
Threat of Harm & $15.5 \%$ & $47.1 \%$ \\
Total & $41.9 \%$ & - \\
\hline
\end{tabular}

Note. *Individual cases may include more than one finding of threats to Child Welfare. For this sample, there were 10,635 youth involved, with 11,944 separate findings of threat to a child's welfare.

Table 3

Demographics by Polyvictimization Status of Threats to Child Welfare

\begin{tabular}{lcccccc}
\hline Measures & \multicolumn{2}{c}{ One Threat } & \multicolumn{2}{c}{$\begin{array}{c}\text { Multiple Threats } \\
\text { (Non-SA) }\end{array}$} & \multicolumn{2}{c}{$\begin{array}{c}\text { Multiple Threats } \\
\text { (SA plus) }\end{array}$} \\
\hline Gender & $N$ & $\%$ & $N$ & $\%$ & $N$ & $\%$ \\
$\quad$ Female & 4,581 & 48.6 & 458 & 44.5 & 138 & 78.4 \\
$\quad$ Male & 4,848 & 51.4 & 572 & 55.5 & 38 & 21.6 \\
Race & & & & & & \\
$\quad$ White & 6,983 & 74.1 & 784 & 76.1 & 137 & 77.9 \\
African American & 732 & 7.8 & 64 & 6.2 & 8 & 4.5 \\
Asian & 117 & 1.2 & 7 & .7 & 2 & 1.1 \\
Hispanic & 974 & 10.3 & 101 & 9.8 & 19 & 10.8 \\
Native American & 238 & 2.5 & 35 & 3.4 & 6 & 3.4 \\
Others/Unknown & 385 & 4.1 & 39 & 3.8 & 4 & 2.3 \\
\hline
\end{tabular}

Note.

1. Multiple Threats (Non-SA) refers to cases where more than one threat had been documented excluding all cases that had any Sexual Abuse/Exploitation threats documented.

2. Multiple Threats (SA plus) refers to cases where more than one threat had been documented and at least one of the threats documented was a Sexual Abuse/Exploitation threat. 
Table 4

Demographics of Pure Threat Types ${ }^{*}$

\begin{tabular}{|c|c|c|c|c|c|c|c|c|c|c|c|c|}
\hline \multirow{3}{*}{ Measures } & \multirow{2}{*}{\multicolumn{2}{|c|}{ Abandonment }} & \multirow{2}{*}{\multicolumn{2}{|c|}{$\begin{array}{l}\text { Mental } \\
\text { Injury }\end{array}$}} & \multirow{2}{*}{\multicolumn{2}{|c|}{ Neglect }} & \multirow{2}{*}{\multicolumn{2}{|c|}{ Physical Abuse }} & \multirow{2}{*}{\multicolumn{2}{|c|}{$\begin{array}{c}\text { Sexual } \\
\text { Abuse/Exploitation }\end{array}$}} & \multirow{2}{*}{\multicolumn{2}{|c|}{ Threat of Harm }} \\
\hline & & & & & & & & & & & & \\
\hline & $N$ & $\%$ & $N$ & $\%$ & $N$ & $\%$ & $N$ & $\%$ & $N$ & $\%$ & $N$ & $\%$ \\
\hline \multicolumn{13}{|l|}{ Gender } \\
\hline Female & 34 & 37.0 & 112 & 43.2 & 682 & 40.8 & 759 & 44.7 & 1,248 & 76.2 & 1,746 & 42.9 \\
\hline Male & 58 & 63.0 & 147 & 56.8 & 989 & 59.2 & 938 & 55.3 & 390 & 23.8 & 2,326 & 57.1 \\
\hline \multicolumn{13}{|l|}{ Race } \\
\hline White & 58 & 63.0 & 197 & 76.1 & 1,206 & 72.2 & 1,287 & 75.8 & 1,269 & 77.5 & 2,966 & 72.8 \\
\hline African American & 11 & 12.0 & 24 & 9.3 & 122 & 7.3 & 136 & 8.0 & 82 & 5.0 & 357 & 8.8 \\
\hline Asian & 1 & 1.1 & 1 & .4 & 15 & .9 & 28 & 1.6 & 17 & 1.0 & 55 & 1.4 \\
\hline Hispanic & 14 & 15.2 & 22 & 8.5 & 198 & 11.8 & 146 & 8.6 & 169 & 10.3 & 425 & 10.4 \\
\hline Native American & 2 & 2.2 & 6 & 2.3 & 57 & 3.4 & 31 & 1.8 & 33 & 2.0 & 109 & 2.7 \\
\hline Others/Unknown & 6 & 6.5 & 9 & 3.5 & 73 & 4.4 & 69 & 4.1 & 68 & 4.2 & 160 & 3.9 \\
\hline
\end{tabular}

Note. * Pure Threat Types refer to threat types were only one time of threat was documented. 
Severity

The results for the cross-tabular analysis for severity types of Crossover and NonCrossover youth are displayed in Table 5. The results indicate that Crossover youth have a higher percentage of status offenses than Non-Crossover youth (15.8\% vs. 6.5\%). These results also show that Crossover youth have a lower percentage of violation offenses compared to Non-crossover youth (18.2\% vs. $32.2 \%)$. For the two remaining offense types, Crossover youth had a higher percentage than Non-Crossover youth for both misdemeanor (53.7\% vs. $49.2 \%)$ and felony (12.3\% vs. $12 \%)$ offenses.

In an effort to investigate misdemeanor and felony offenses more in-depth, Table 6 shows the percentage of each of the offenses broken down by person and property crime, as well as crime class, and type. The results indicate that a higher proportion of the offenses alleged against Crossover youth are person crimes than Non-Crossover youth, regardless of whether it was a misdemeanor or felony. In fact, person crimes account for $14.2 \%$ of all offenses for Crossover youth and only $10.1 \%$ for Non-Crossover youth. These results also indicate that compared with Non-Crossover youth, a higher proportion of the allegations against Crossover youth are in the most severe felonies.

Table 7 represents the linear regression of severity scores of Crossover youth, controlling for certain demographic characteristics. The results indicate that Crossover youth have higher severity scores than Non-Crossover youth, even after controlling for important demographics. While females have lower severity scores than male, as well as youth that are older have lower severity scores. It is also important to note that African Americans tend to have the highest severity scores of offenses relative to all other 
demographics. All these results were statistically significant (Tables 5-7 are presented in the next pages).

Table 5

Offense Type for Crossover and Non-Crossover Youth

\begin{tabular}{lcccccc}
\hline Measures & \multicolumn{2}{c}{ Crossover Youth } & \multicolumn{2}{c}{ Non-Crossover Youth } & \multicolumn{2}{c}{ Totals } \\
\cline { 2 - 5 } & $N$ & $\%$ & $N$ & $\%$ & $N$ & $\%$ \\
\hline Status & 1,684 & 15.8 & 9,169 & 6.5 & 10,853 & 7.1 \\
Violation & 1,935 & 18.2 & 45,495 & 32.2 & 47,430 & 31.2 \\
Misdemeanor & 5,708 & 53.7 & 69,519 & 49.2 & 75,227 & 49.5 \\
Felony & 1,304 & 12.3 & 16,986 & 12 & 18,290 & 12 \\
Other & 4 & 0 & 56 & .1 & 60 & .2 \\
Totals & 10,635 & 100 & 141,225 & 100 & 151,860 & 100 \\
\hline
\end{tabular}

Note. (chi-square Pearson value $=1888.028, \mathrm{p}=.000$ )

Table 6

Severity Code for Crossover and Non-Crossover Youth

\begin{tabular}{lcccccc} 
Measures & \multicolumn{2}{c}{ Crossover Youth } & \multicolumn{2}{c}{ Non-Crossover Youth } & \multicolumn{2}{c}{ Totals } \\
\cline { 2 - 5 } & $N$ & $\%$ & $N$ & $\%$ & $\%$ \\
\hline Status Offense & 1,684 & 15.8 & 9,170 & 6.5 & 10,854 & 7.1 \\
Violation & 1,937 & 18.2 & 45,506 & 32.2 & 47,443 & 31.2 \\
Property Crime & & & & & & \\
C Misdemeanor & 1,835 & 17.3 & 25,840 & 18.3 & 27,675 & 18.2 \\
B Misdemeanor & 949 & 8.9 & 10,069 & 7.1 & 11,018 & 7.3 \\
A Misdemeanor & 1,871 & 17.6 & 23,602 & 16.7 & 25,473 & 16.8 \\
Person Crime & & & & & & \\
A Misdemeanor & 1,020 & 9.6 & 9,608 & 6.8 & 10,628 & 7 \\
Property Crime & & & & & & \\
C Felony & 557 & 5.2 & 8,744 & 6.2 & 9,301 & 6.1 \\
B Felony & 43 & .4 & 884 & .6 & 927 & .6 \\
A Felony & 220 & 2.1 & 2,801 & 2 & 3,021 & 2 \\
Person Crime & & & & & & \\
C Felony & 160 & 1.5 & 1,909 & 1.4 & 2,069 & 1.4 \\
B Felony & 178 & 1.7 & 1,641 & 1.2 & 1,819 & 1.2 \\
A Felony & 144 & 1.4 & 1,014 & .7 & 1,158 & .8 \\
Other & 37 & .3 & 437 & .3 & 474 & .3 \\
Totals & 10,635 & 100 & 141,225 & 100 & 151,860 & 100 \\
\hline
\end{tabular}

Note: (chi-square Pearson value $=2107.451, \mathrm{p}=.000$ ) 
Table 7

Linear Regression of Severity of Referrals $(N=151,860)$

\begin{tabular}{|c|c|c|c|c|c|c|c|c|}
\hline \multirow[t]{2}{*}{ Measures } & \multicolumn{2}{|c|}{ Model 1} & \multicolumn{2}{|c|}{ Model 2} & \multicolumn{2}{|c|}{ Model 3} & \multicolumn{2}{|c|}{ Model 4} \\
\hline & $\beta$ & $\mathrm{SE}$ & $\beta$ & $\mathrm{SE}$ & $\beta$ & SE & $\beta$ & SE \\
\hline Crossover $^{1}$ & $.295 * * *$ & .040 & $.485 * * *$ & .039 & $.450 * * *$ & .039 & $.102 * *$ & .040 \\
\hline \multicolumn{9}{|l|}{ Gender (male) } \\
\hline Female & & & $-1.394 * * *$ & .021 & $-1.380 * * *$ & .021 & $-1.341 * * *$ & .021 \\
\hline \multicolumn{9}{|l|}{ Race (white) } \\
\hline African American & & & & & $1.276 * * *$ & .051 & $1.189 * * *$ & .051 \\
\hline Asian & & & & & $.696 * * *$ & .080 & $.738 * * *$ & .079 \\
\hline Hispanic & & & & & $.588 * * *$ & .031 & $.519 * * *$ & .030 \\
\hline Native American & & & & & $.551 * * *$ & .076 & $.404 * * *$ & .076 \\
\hline Others/Unknown & & & & & $.200 * * *$ & .045 & $.222 * * *$ & .045 \\
\hline Age, centered on 10 & & & & & & & $-.268 * * *$ & .006 \\
\hline Constant & $5.148 * * *$ & .011 & $5.637 * * *$ & .013 & $5.476 * * *$ & .014 & $6.746 * * *$ & .030 \\
\hline
\end{tabular}

Note. $* \mathrm{p} \leq .05, * * \mathrm{p} \leq .01, * * * \mathrm{p} \leq .001$

1. Models using each specific child welfare threat type did not add significantly to the overall predictability; therefore, overall Crossover type was used. 


\section{Dispositions}

The remaining analyses explore the outcomes of youths within the juvenile justice system after their first arrest. Table 8 represents overall case outcomes by Crossover status. It is important to note that table 8 includes multiple decision points within the juvenile justice system. Therefore when interpreting the results, it is only relevant to make comparisons between Crossover status for that particular outcome, and not compare multiple outcomes to each other. Crossover youth represent a higher percentage of cases than Non-Crossover youth that are reviewed and closed (47.6\% vs. $42.5 \%)$, dismissed (7.8\% vs. $6.2 \%)$, and plea bargained (1.7\% vs. $1.3 \%)$. They also have a higher percentage of cases where the outcome is a custody transferred to other agency $(1.0 \%$ vs. $.5 \%)$, or the youth correctional facility (.8\% vs. .3\%). However, Crossover youth have a lower percentage of cases that receive diversion $(32.3 \%$ vs. $39.4 \%)$, or receive an adult sentence $(.3 \%$ vs. . $7 \%)$ than Non-Crossover youth. All of these case outcomes were statistically significant. 
Table 8

Overall Case Outcomes by Crossover Status

\begin{tabular}{|c|c|c|c|c|c|c|}
\hline \multirow[t]{2}{*}{ Measures } & \multicolumn{2}{|c|}{$\begin{array}{l}\text { Crossover } \\
\text { Youth }\end{array}$} & \multicolumn{2}{|c|}{$\begin{array}{c}\text { Non-Crossover } \\
\text { Youth }\end{array}$} & \multicolumn{2}{|c|}{ Totals } \\
\hline & $N$ & $\%$ & $N$ & $\%$ & $N$ & $\%$ \\
\hline \multicolumn{7}{|l|}{ Not Petitioned } \\
\hline Review \& Close & 5,058 & $47.5_{\mathrm{a}}$ & 60,020 & $42.5_{b}$ & 65,078 & 42.8 \\
\hline Diversion & 3,431 & $32.3_{\mathrm{a}}$ & 55,710 & $39.4_{b}$ & 59,141 & 38.9 \\
\hline \multicolumn{7}{|l|}{ Petitioned } \\
\hline \multicolumn{7}{|l|}{ Alternative Closure } \\
\hline Dismissal & 827 & $7.8_{a}$ & 8,768 & $6.2_{\mathrm{b}}$ & 9,595 & 6.3 \\
\hline Plea Bargain & 178 & $1.7_{\mathrm{a}}$ & 1,889 & $1.3_{\mathrm{b}}$ & 2,067 & 1.4 \\
\hline \multicolumn{7}{|l|}{ Adjudicated Delinquent } \\
\hline Probation & 917 & $8.6_{a}$ & 12,743 & $9 \mathrm{a}$ & 13,660 & 9 \\
\hline Transfer to Other Agency & 109 & $1.0_{\mathrm{a}}$ & 638 & $.5 \mathrm{~b}$ & 747 & .5 \\
\hline Youth Correctional Facility & 80 & $.8_{\mathrm{a}}$ & 476 & $.3 \mathrm{~b}$ & 556 & .4 \\
\hline \multicolumn{7}{|l|}{ Adult Court } \\
\hline Adult Sentence & 34 & $.3_{\mathrm{a}}$ & 975 & $.7_{\mathrm{b}}$ & 1,009 & .7 \\
\hline Other & 1 & $0_{\mathrm{a}}$ & 6 & $0_{\mathrm{a}}$ & 7 & 0 \\
\hline Totals & 10,635 & 100 & 141,225 & 100 & 151,860 & 100 \\
\hline
\end{tabular}

The remaining tables separate case dispositions at multiple decision points within the juvenile justice system. Table 9 reports all case outcomes, and whether or not they were petitioned. The majority of all cases $(81.8 \%)$ are not petitioned. When examining differences among Crossover status, Crossover youth have a slightly lower percentage than Non-Crossover youth of cases not petitioned (79.8\% vs. $82 \%)$ and a slightly higher percentage of cases petitioned (20.2\% vs. $18 \%)$. Table 10 breaks down case dispositions for those cases not petitioned that received an informal processing decision. Among cases not petitioned, Crossover youth have $59.6 \%$ of cases reviewed and closed, and $40.4 \%$ of cases receiving diversion. While Non-Crossover youth have $51.9 \%$ reviewed and closed, and $48.1 \%$ of cases receiving diversion. 
Table 11 highlights case dispositions for those petitioned that received a formal processing decision. Among petitioned cases, Crossover youth had $46.9 \%$ of their cases receiving an alternative closure outcome, $51.6 \%$ of their cases receiving an adjudicated delinquent outcome, and $1.6 \%$ of their cases receiving an adult court outcome. Among petitioned cases for Non-crossover youth, $41.8 \%$ of their cases received an alternative closure outcome, $54.4 \%$ of their cases received an adjudicated delinquent outcome, and $3.8 \%$ of their cases receiving an adult court outcome.

Table 12 represents the breakdown of case dispositions that received an adjudicated delinquent outcome. The majority of all adjudicated delinquent outcomes (91.3\%) received probation. When examining differences among Crossover status, Crossover youth had a lower percentage than Non-Crossover youth of cases receive probation ( $82.9 \%$ vs. $92 \%)$, but a higher percentage of case outcomes resulting in a custody transfer to another agency (9.9\% vs. 4.6\%). Crossover youth also had a higher percentage than Non-crossover youth of case outcomes resulting in a youth correctional facility outcome (7.2\% vs. $3.4 \%)$. 
Table 9

Overall Case Outcomes for Not Petitioned and Petitioned by Crossover Status

\begin{tabular}{lcccccc}
\hline Measures & \multicolumn{2}{c}{ Crossover Youth } & \multicolumn{2}{c}{$\begin{array}{c}\text { Non-Crossover } \\
\text { Youth }\end{array}$} & \multicolumn{2}{c}{ Totals } \\
\cline { 2 - 5 } & $N$ & $\%$ & $N$ & $\%$ & $N$ & $\%$ \\
\hline Not Petitioned & 8,489 & $79.8_{\mathrm{a}}$ & 115,730 & $82_{\mathrm{b}}$ & 124,219 & 81.8 \\
Petitioned & 2,146 & $20.2_{\mathrm{a}}$ & 25,495 & $18_{\mathrm{b}}$ & 27,641 & 18.2 \\
$\quad$ Totals & 10,635 & 100 & 141,225 & 100 & 151,860 & 100 \\
\hline
\end{tabular}

Note: $($ chi-square Pearson value $=29.910, \mathrm{p}=.000$ )

Table 10

Case Dispositions among Not Petitioned Cases by Crossover Status

\begin{tabular}{|c|c|c|c|c|c|c|}
\hline \multirow[t]{2}{*}{ Measures } & \multicolumn{2}{|c|}{ Crossover Youth } & \multicolumn{2}{|c|}{$\begin{array}{c}\text { Non-Crossover } \\
\text { Youth }\end{array}$} & \multicolumn{2}{|c|}{ Totals } \\
\hline & $N$ & $\%$ & $N$ & $\%$ & $N$ & $\%$ \\
\hline \multicolumn{7}{|l|}{ Not Petitioned } \\
\hline Review \& Close & 5,058 & $59.6_{a}$ & 60,020 & $51.9_{b}$ & 65,078 & 52.4 \\
\hline Diversion & 3,431 & $40.4_{a}$ & 55,710 & $48.1_{b}$ & 59,141 & 47.6 \\
\hline Totals & 8,489 & 100 & 115,730 & 100 & 124,219 & 100 \\
\hline
\end{tabular}

Note: $($ chi-square Pearson value $=189.018, \mathrm{p}=.000)$

Table 11

Case Dispositions among Petitioned Cases by Crossover Status

\begin{tabular}{lcccccc}
\hline Measures & \multicolumn{2}{c}{ Crossover Youth } & \multicolumn{2}{c}{$\begin{array}{c}\text { Non-Crossover } \\
\text { Youth }\end{array}$} & \multicolumn{2}{c}{ Totals } \\
\cline { 2 - 5 } & $N$ & $\%$ & $N$ & $\%$ & $N$ \\
\hline Petitioned & & & & & \\
$\quad$ Alternative Closure & 1,005 & $46.9_{\mathrm{a}}$ & 10,657 & $41.8_{\mathrm{b}}$ & 11,662 & 42.2 \\
Adjudicated Delinquent & 1,106 & $51.6_{\mathrm{a}}$ & 13,857 & $54.4_{\mathrm{b}}$ & 14,963 & 54.1 \\
Adult Court & 34 & $1.6_{\mathrm{a}}$ & 975 & $3.8 \mathrm{~b}$ & 1,009 & 3.7 \\
Totals & 2,145 & 100 & 25,489 & 100 & 27,634 & 100 \\
\hline
\end{tabular}

Note: (chi-square Pearson value $=41.984, \mathrm{p}=.000$ ) 
Table 12

Case Dispositions among Adjudicated Delinquent Cases by Crossover Status

\begin{tabular}{lccccccc} 
Measures & \multicolumn{2}{c}{$\begin{array}{c}\text { Crossover } \\
\text { Youth }\end{array}$} & \multicolumn{2}{c}{$\begin{array}{c}\text { Non-Crossover } \\
\text { Youth }\end{array}$} & \multicolumn{2}{c}{ Totals } \\
\cline { 2 - 5 } & $N$ & $\%$ & $N$ & $\%$ & & $\%$ \\
\hline Adjudicated Delinquent & & & & & & \\
$\quad$ Probation & 917 & $82.9 \mathrm{a}$ & 12,743 & $92_{\mathrm{b}}$ & 13,660 & 91.3 \\
Transfer to Other Agency & 109 & $9.9_{\mathrm{a}}$ & 638 & $4.6_{\mathrm{b}}$ & 747 & 5 \\
$\quad$ Youth Correctional Facility & 80 & $7.2_{\mathrm{a}}$ & 476 & $3.4_{\mathrm{b}}$ & 556 & 3.7 \\
$\quad$ Totals & 1,106 & 100 & 13,857 & 100 & 14,963 & 100 \\
\hline
\end{tabular}

Note: (chi-square Pearson value $=105.527, \mathrm{p}=.000$ ) 


\section{Chapter 6: Discussion}

The objectives of the current study were (1) to determine if Crossover youth represent a unique demographic subpopulation within the juvenile justice system, (2) to determine if Crossover youth have a higher severity score for offenses than NonCrossover youth, and (3) to determine whether involvement with the child welfare system appears to have an impact on processing decisions (dispositions) in the juvenile justice system.

With regard to demographic characteristics, juvenile offenders coming from the child welfare system are unique, relative to juvenile offenders coming from other referral sources. At the time of first referral, Crossover youth are more likely to be female, African American, and significantly younger than Non-Crossover youth (Table 1). All of these findings are consistent with prior research (Herz, et al., 2007; Herz \& Ryan, 2008; Ryan et al., 2007).

It was important to examine the breakdown of child welfare documented threat types to assess the population of the child welfare youth beyond demographics. The largest threat type to child welfare youth was the threat of harm; followed by neglect, physical abuse, and sexual abuse/exploitation all being highly reported threat types as well (Table 2). As previously stated, the threat categories are not mutually exclusive; therefore, more than one type of threat could be documented for each youth. With regard to demographic characteristics of threat types by polyvictimization status, Crossover youth with only one threat type documented are similar to that of the general population. Crossover youth with multiple threat types in which one of those threats is sexual abuse/exploitation had a higher percentage of females and African Americans (Table 3). 
Examining only pure threat types, Abandonment produced some interesting findings with a lower percentage of females and Whites and a higher percentage of Hispanics (Table 4). Besides the unique findings of demographic characteristics for multiple threats in which one of those threats is sexual abuse/exploitation and the pure abandonment threat type, the individual Crossover threat types did not produce substantive results when included in later analyses. Therefore, as previously mentioned, they were not included in later tables and only overall Crossover youth type was used.

Crossover youth have a significantly higher percentage of status offenses than Non-Crossover youth in first-time referrals (Table 5). Dependency and status offenses include runaway, beyond parental control, and behavior to endanger self or others. Hence, it is not that surprising that youth involved with child welfare system represent more of these offense types. Such offenses could have precipitated the child welfare involvement. However, for violation offenses, Crossover youth have a much lower percentage of these types of offenses than Non-Crossover youth. Violation offenses refer to public order offenses like disorderly conduct, harassment, or offenses regarding curfew, tobacco, and substance/alcohol use. It is interesting to note that for first-time referrals Non-Crossover youth represent almost double the percentage of violation offenses compared to Crossover youth.

The current study also sought to shed light on the inconsistency in the literature regarding whether Crossover youth allegedly commit more violent or serious crimes. Examining severity codes based on crime category (person or property crime), class and type, the results found that Crossover youth commit more person crimes than NonCrossover youth, regardless of whether it was a misdemeanor or felony (Table 6). The 
study also found that Crossover youth commit a higher percentage of all the most severe felonies, compared to Non-Crossover youth.

Crossover youth also have higher severity scores for offenses, even when controlling for demographics (Table 7). These results add to the previous research that found Crossover youth are more likely to commit violent or serious crimes than those with no history of abuse or neglect (Thornberry, 2008). When examining demographics alone females have lower severity scores, therefore, they are more likely to commit property or drug crimes, which is consistent with previous research (Bilchik \& Nash, 2008; Ryan et al., 2007). In terms of age, the current study found that youth with higher severity scores tend to be younger; this is expected knowing that Crossover youth have higher severity scores and tend to be younger. Along with all these results being statistically significant, it is also important to note that African Americans had the largest coefficient, further highlighting the disparity among this population.

The current study investigated whether involvement with the child welfare system appears to have an impact on processing decisions (dispositions) in the juvenile justice system after their first arrest. Overall, Crossover youth had more case dispositions dismissed, and reviewed and closed, than Non-Crossover youth (Table 8). This could be due to the fact that Crossover youth are likely to already be under some sort of supervision within child welfare, so rather than using double the resources it may be more beneficial for the juvenile justice system to dismiss, or review and close the case. Crossover youth also had more cases receive a transfer to another agency, or receive an outcome that required them to go to a youth correctional facility than Non-Crossover youth, which will be discussed in further detail below. However, Crossover youth have a 
lower percentage of case outcomes that go through diversion or receive an adult sentence, than Non-Crossover youth. Though, with regard to receiving an adult sentence, these results are not surprising. When considering the relationship between age and adult court dispositions, it is expected that age would be the highest determining factor in whether an offender receives an adult court disposition. Since we know that Crossover youth are significantly younger than Non-Crossover youth at time of their first offense, this outcome would be somewhat expected.

Case dispositions were also examined at multiple decision points, allowing for comparisons of case outcomes at that particular decision point (Tables 9-12). Results indicate that the majority of cases for both Crossover and Non-crossover youth were not petitioned. However, Crossover youth were found to have a slightly higher percentage than Non-crossover youth of cases petitioned. Which gives support to the hypothesis that Crossover youth are expected to have a more intense disposition outcome, when compared to Non-Crossover youth.

Results also indicated that when examining differences, particularly among adjudicated delinquent outcomes, Crossover youth had a significantly higher percentage of cases receive a sanction that placed them in a youth correctional facility than NonCrossover youth. A sanction to a youth correctional facility is arguably the most intense disposition outcome, besides being sentenced to adult court. This is consistent with the research that has shown court officials to impose more severe sanctions when youth are not perceived to come from "good" families (Feld, 1999). This finding also may build on the few studies that focus on maltreated children in the juvenile justice system indicating 
that the status as a Crossover youth negatively influences decision making (Conger \& Ross, 2001, Freundlich \& Morris, 2004).

Several limitations are worth noting regarding the present study. First, as previously mentioned, some cases had to be deleted for missing or recoding purposes. Precautions were taken by running cross-tabular analyses to verify that there were no patterns present in the data that was to be deleted. Fortunately, the cases that were deleted represent such a small part of the sample that this did not appear to skew the data. Another potential limitation to this study is that the child welfare and delinquency records were examined over the same 12-year period. Meaning that delinquent youth that had child welfare status before then, or child welfare youth that have been exposed to the juvenile justice system after that period would not show up in this study. A past study of children who had experienced abuse indicated that after five years, 14 percent had appeared in court for delinquency or a status offense, and after ten years 32 percent had been adjudicated (Bolton et al., 1977). Therefore, there may be an underestimation of how prevalent child welfare youth commit delinquent acts. To further add to this point is the fact that child abuse and neglect is believed to be significantly under-reported. As a result, because this study only used 'founded' abuse and neglect from the child welfare system there may be many more abused and neglected youth within the juvenile justice system than captured by this sample.

Finally, the results of the present study point to implications and areas of future research. Findings suggest there is a disparity between child welfare referrals and nonchild welfare referrals. However, there is still much to be learned about the relationship between child welfare and juvenile justice, particularly the reason why youths cross over 
and how to better serve them within the child welfare system to minimize their risk of juvenile justice system involvement. More research needs to be done to determine if other variables such as demographics or offense categories explain more of the relationship between the offender and the disposition level. This may shed light on whether the disparity is due to the fact that crossover youth are committing more serious offenses or if in fact there is a bias that impact processing decisions.

Also, it would be valuable to explore Crossover youth beyond their first-referral, to investigate whether there are long-term effects of being a Crossover youth, such as if they are at a higher risk of recidivism. There is much more to learn about who the Crossover offenders are beyond demographic information. Examining their referral reasons for child welfare involvement in more detail may shed more light on the unique subpopulation they represent in the juvenile justice system. Future research should focus on all these areas, hopefully bridging the gap of understanding of this unique subpopulation. Policy makers may then be able to make more informed decisions about policies and laws effecting this particular population. Future research may also help in influencing the development of specific programming and services targeted towards this unique subpopulation with the goal of reducing the risk of delinquency. Allowing the best future for our youth and our communities. 


\section{References}

Armstrong, M. L. (1998). Adolescent pathways: Exploring the intersections between child welfare and juvenile justice, PINS, and mental health. New York: Vera Institute of Justice.

Bilchik, S., \& Nash, J. M. (2008). Child welfare and juvenile justice: Two sides of the same coin. Juvenile and Family Justice Today, 16-20.

Bolton, F.G., Reich, J.W., \& Guiterris, S.B. (1977). Delinquency patterns in maltreated children and siblings. Victimology, 2, 349-357.

Brezina, T. (1998). Adolescent maltreatment and delinquency: The question of intervening processes. Journal of Research in Crime and Delinquency, 35, 71-89.

Conger, D., \& Ross, T. (2001). Reducing the foster care bias in juvenile detention decisions: The impact of project confirm. New York: Vera Institute of Justice.

Feld, B. (1999). Bad kids: Race and the transformation of the juvenile court. New York: Oxford University Press.

Freundlich, M., \& Morris, L. (2004). Youth involvement in the child welfare and juvenile justice systems: A case of double jeopardy? Washington, DC: Child Welfare League of America.

Herz, D., \& Ryan, J.P. (2008). Building multisystem approaches in child welfare and juvenile justice. Washington, DC: Center for Juvenile Justice Reform.

Herz, D. C., Ryan, J. P., \& Bilchik, S. (2010). Challenges facing crossover youth: An examination of juvenile-justice decision making and recidivism. Family Court Review, 48, 305-321. 
Kelley, B. T., Thornberry, T.P., Smith, C.A. (1997). In the wake of childhood maltreatment. Juvenile Justice Bulletin, 1-16.

Lewis, D.O. (1983). Neuropsychiatric vulnerabilities and violent juvenile delinquency. Psychiatric Clinics of North America 6, 707-714.

Maxfield, M. G., Widom, C. S. (1996). The cycle of violence: Revisited six years later. Archives of Pediatrics and Adolescent Medicine, 150, 390-395.

Nash, J. M., \& Bilchik, S. (2009). Child Welfare and Juvenile Justice-Two Sides of the Same Coin, Part II. Juvenile and Family Justice Today, 23-25.

Office of Juvenile Justice and Delinquency Prevention. (1998). Serious and Violent Juvenile Offenders. Bulletin. Washington, DC: U.S. Department of Justice, Office of Justice Programs, Office of Juvenile Justice and Delinquency Prevention.

Center on Juvenile and Criminal Justice. (2011). Renewing Juvenile Justice. Sacramento: Sierra Health Foundation.

Ryan, J. P., Herz, D., Hernandez, P. M., \& Marshall, J. M. (2007). Maltreatment and delinquency: Investigating child welfare bias in juvenile justice processing. Children and Youth Services Review, 29, 1035-1050.

Ryan, J. P., Testa, M. F. (2005). Child maltreatment and juvenile delinquency: Investigating the role of placement and placement stability. Children and Youth Services Review, 27, 227-249.

Scrivner, K. W. (2002). Crossover kids: The dilemma of the abused delinquent. Family Court Review, 40, 135-152.

Smith, C., \& Thornberry, T. P. (1995). The relationship between childhood maltreatment and adolescent involvement in delinquency. Criminology, 33, 451-481. 
Thornberry, T.P. (2008, May 7). Co-occurrence of problem behaviors among adolescents. Presented at Multi-System Approaches in Child Welfare and Juvenile Justice: Wingspread Conference.

U.S. Department of Health and Human Services, Administration for Children and Families, Administration on Children Youth and Families Children's Bureau [DHHS] (2008). Child Maltreatment 2006. Washington, DC: U.S. Government Printing Office. Retrieved from http://www.acf.hhs.gov/programs/cb/pubs/cm06/index.htm

Widom, C. S. (1989). The cycle of violence. Science, 244, 160-166.

Widom, C. S. (1992). The cycle of violence (Research in brief). Washington, DC: U.S. Department of Justice, National Institute of Justice.

Widom, C. S. (2003). Understanding child maltreatment and juvenile delinquency: The research. Understanding child maltreatment and juvenile delinquency: From research to effective program, practice, and systemic solutions, 1-10.

Widom, C. S., Maxfield, M.G. (2001) An update on "the cycle of violence". National Institute of Justice. Research in Brief, 1-8. 
Appendix A—Juvenile Justice Information Systems Severity Scores

(adopted, Oregon Juvenile Department Directors Association, May 18, 2000)

\begin{tabular}{|l|c|c|}
\hline \multicolumn{1}{|c|}{ Crime Category } & Class \& Type & $\begin{array}{c}\text { Severity } \\
\text { Score }\end{array}$ \\
\hline Person & Murder* & 19 \\
\hline Person & A Felony & 18 \\
\hline Person & B Felony & 17 \\
\hline Person & U Felony & 16 \\
\hline Person & A Felony & 15 \\
\hline $\begin{array}{l}\text { Property } \\
\text { Other Criminal (Behavioral) }\end{array}$ & B Felony & 14 \\
\hline $\begin{array}{l}\text { Property } \\
\text { Other Criminal (Behavioral) }\end{array}$ & C Felony & 12 \\
\hline $\begin{array}{l}\text { Property } \\
\text { Other Criminal (Behavioral) }\end{array}$ & U Felony & 11 \\
\hline $\begin{array}{l}\text { Property } \\
\text { Other Criminal (Behavioral) }\end{array}$ & A Misdemeanor & 10 \\
\hline Person & B Misdemeanor & 9 \\
\hline Person & C Misdemeanor & 8 \\
\hline Person & U Misdemeanor & 7 \\
\hline Person & A Misdemeanor & 6 \\
\hline $\begin{array}{l}\text { Property } \\
\text { Other Criminal (currently named Behavioral) }\end{array}$ & B Misdemeanor & 5 \\
\hline $\begin{array}{l}\text { Property } \\
\text { Other Criminal (currently named Behavioral) }\end{array}$ & C Misdemeanor & 4 \\
\hline $\begin{array}{l}\text { Property } \\
\text { Other Criminal (currently named Behavioral) }\end{array}$ & U Misdemeanor & 3 \\
\hline $\begin{array}{l}\text { Property } \\
\text { Other Criminal (currently named Behavioral) }\end{array}$ & Violation & 2 \\
\hline Non Criminal & Status Offense & 1 \\
\hline & Abe Mur in \\
\hline
\end{tabular}

Note: * Aggravated Murder, Murder, Murder by Abuse, Murder in the Course of a Crime, Murder Intentional, Criminal Homicide, and Treason have the Type of Murder (instead of Felony), in order to obtain the highest severity score.

Source: Juvenile Justice Information Systems Data \& Evaluation Reports 
Appendix B-Disposition Categories

Disposition Categories: These reports categories dispositions according to a standard developed by the JJIS Data and Evaluation Committee, and modeled after national reporting standards. Detailed dispositions have been grouped into the disposition reporting categories.

For all reports, dispositions are grouped into categories consistent with national reporting categories as follows. Categories are listed from least to most intense level of juvenile justice intervention.

\begin{tabular}{|c|c|c|}
\hline \multirow{8}{*}{ 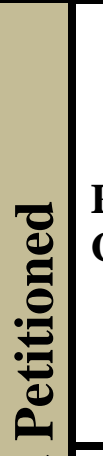 } & \multirow{8}{*}{$\begin{array}{l}\text { Review and } \\
\text { Close }\end{array}$} & No Jurisdiction \\
\hline & & Referred to Another Agency \\
\hline & & Review \& Close \\
\hline & & Warning \\
\hline & & Divert \& Close \\
\hline & & Intake Office Contact \& Close \\
\hline & & Rejected by DA/Juvenile Department \\
\hline & & Alternative Process \\
\hline \multirow{5}{*}{$\overrightarrow{\ddot{\theta}}$} & \multirow{5}{*}{$\begin{array}{l}\text { Authorized } \\
\text { Diversion } \\
\text { Programs or } \\
\text { Other } \\
\text { Informal } \\
\text { Disposition }\end{array}$} & Diversion Supervision \\
\hline & & Diversion-Youth Court \\
\hline & & Diversion-Traffic/Municipal Court \\
\hline & & Informal Sanction(s)/Supervision \\
\hline & & Formal Accountability Agreement \\
\hline \multirow{10}{*}{ 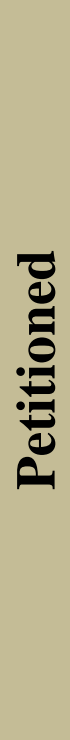 } & Dismissed & Dismissed \\
\hline & $\begin{array}{l}\text { Alternative } \\
\text { Process }\end{array}$ & Plea Bargain or Alternative Process \\
\hline & \multirow{6}{*}{$\begin{array}{l}\text { Adjudicated } \\
\text { Delinquent }\end{array}$} & Formal Sanction \\
\hline & & Probation \\
\hline & & Commit/Custody to Other Agency (Non-Youth Authority) \\
\hline & & $\begin{array}{l}\text { Probation and Commit/Custody to Other Agency (Non- } \\
\text { Youth Authority) }\end{array}$ \\
\hline & & $\begin{array}{l}\text { Probation and Youth Authority Commitment for Community } \\
\text { Placement }\end{array}$ \\
\hline & & $\begin{array}{l}\text { Youth Authority Commitment for Youth Correctional } \\
\text { Facility Placement }\end{array}$ \\
\hline & \multirow{2}{*}{ Adult Court } & Waived/Transfer \\
\hline & & Adult Sentence \\
\hline
\end{tabular}

Source: Juvenile Justice Information Systems Data \& Evaluation Reports 
Appendix C-Human Subjects Approval

\section{Portland State University HSRRC Memorandum}

To: Courtney Shrifter

From: HSRRC 2012

Date: February 28, 2012

Re: $\quad$ HSRRC waived review of your application titled, "Examining the Differences of Child Welfare Youth within Juvenile Justice" (HSRRC Proposal \#122063)

Your proposal is exempt from further Human Subjects Research Review Committee review, and you may proceed with the study.

Even with the exemption above, it was necessary by University policy for you to notify this Committee of the proposed research, and we appreciate your timely attention to this matter. If you make changes in the research protocol, the Committee must be notified in writing, and changes must be approved before being implemented.

If you have questions or concerns, please contact the HSRRC at Research and Strategic Partnerships, Market Center Building, $6^{\text {th }}$ Floor.

cc: Brian Renauer

Waiver memo 